\title{
The antimicrobial activity of the macrophage metabolite itaconate is
}

\section{synergistic with acidity}

Dustin Duncan ${ }^{\mathrm{a}}$, Andréanne Lupien ${ }^{\mathrm{b}, \mathrm{c}}$, Marcel A. Behr ${ }^{\mathrm{b}, \mathrm{c}}$ and Karine Auclair ${ }^{\mathrm{a}} \#$

aDepartment of Chemistry, McGill University, Montreal, Quebec, Canada

${ }^{b}$ Department of Medicine, McGill University, Montreal, Quebec, Canada

${ }^{\mathrm{C} M c G i l l}$ International TB Centre, McGill University, Montreal, Quebec, Canada

\#Address correspondence to Dr. Karine Auclair, karine.auclair@mcgill.ca 


\begin{abstract}
The production of itaconate by macrophages was only discovered in 2011. A rapidly increasing number of studies have since revealed essential biological roles for itaconate, ranging from antimicrobial to immunomodulator. Itaconate has been estimated to reach low-millimolar concentrations in activated macrophages, including those within infected lungs and brains, whereas itaconate's MIC towards several bacterial strains were measured to be in the low-tomid-millimolar range, casting some doubts on the antibacterial role of itaconate in vivo. Several of these investigations, in particular those measuring MIC values of itaconate or itaconic acid, have however tended to ignore the high acidity of this small diacid (pKas 3.85 and 5.45), thereby potentially biasing the MIC measurements. We report herein that: 1) at high concentration, itaconic acid can significantly reduce the $\mathrm{pH}$ of growth media; 2) the antibacterial activity of itaconate increases in a synergistic manner with acidity; 3 ) this synergistic effect is not simply due to increased permeability of monoanionic itaconate; 4) considering that the MIC of itaconate is many fold lower under acidic conditions for all strains tested, itaconate may serve an antimicrobial role, particularly in acidic vesicles such as the phagolysosome; and 5) differential growth behavior in the presence of disodium itaconate versus itaconic acid may serve to rapidly screen bacterial strains for their ability to metabolize itaconate. Our results further support the hypothesis that inhibitors of itaconate degradation in bacteria may provide a new strategy to treat infections.
\end{abstract}




\section{Introduction}

Itaconate (Figure 1) is a 1,4-diacid produced by macrophages upon classical activation by bacterial lipopolysaccharides (LPS).(1) The presence of LPS leads to upregulation of the immuneresponsive gene 1 (irg1), translated to the protein cis-aconitate decarboxylase (also known as Irg1, Acod1 or Cad), which produces itaconate from the citric acid cycle intermediate cisaconitate.(2)

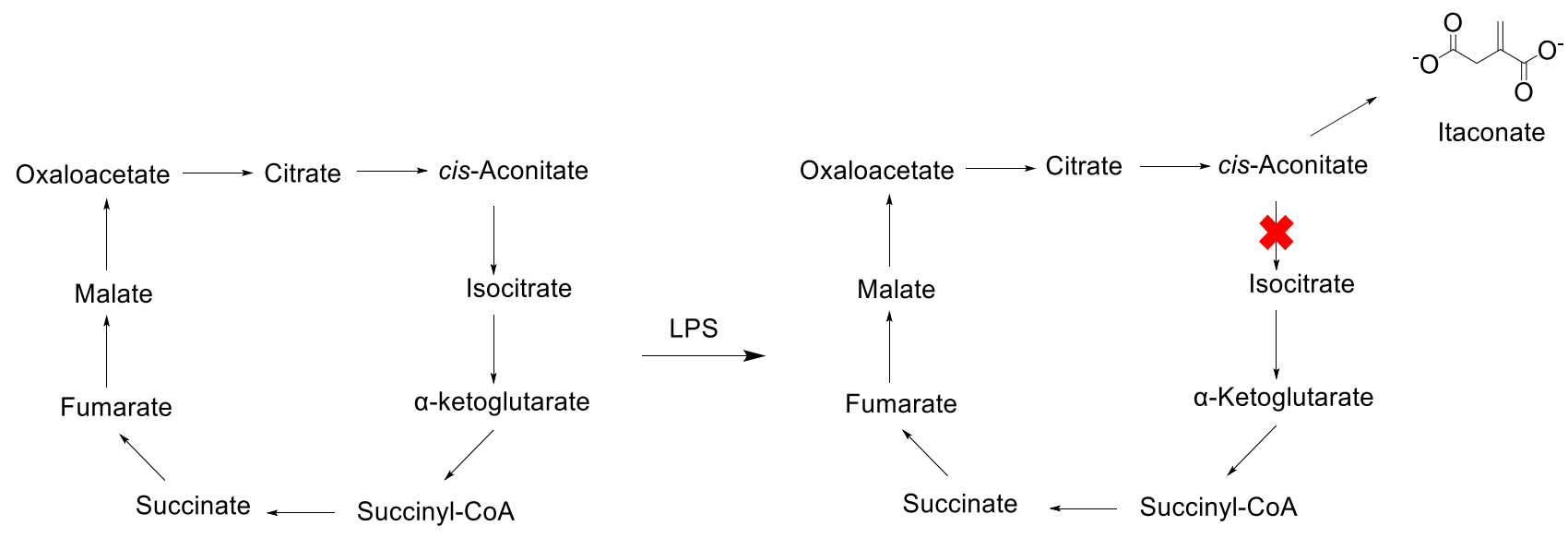

Figure 1: Within macrophages, diversion of the citric acid cycle after exposure to lipopolysaccharides (LPS) produces itaconate

Whereas itaconate was recently demonstrated to have a complex immunomodulatory effect on mammalian cells $(3,4)$ (e.g. inhibition of succinate dehydrogenase,(5) downregulation of glycolysis,(6) programming macrophages for communication to other leukocytes,(7) and other immunoregulatory effects(8-12)), other reports have suggested that itaconate produced by macrophages may contribute to the antimicrobial activity of the innate immune system. $(2,13)$ Consistent with the latter role, an itaconate degradation pathway has been identified in some bacterial species known to proliferate in macrophages.(14) Interestingly, Hammerer et al. have 
reported a small molecule able to resensitize bacteria to itaconate, and suggested that inhibiting itaconate degradation in bacteria might be a new strategy to treat infections.(15)

Itaconate is an inhibitor of bacterial isocitrate lyase (Icl) with a $K_{i}$ of $0.9 \mu \mathrm{M}$ for the Pseudomonas indigofera isoform,(16) and $K_{i}$ values of $120 \mu \mathrm{M}$ and $220 \mu \mathrm{M}$ for Icl1 and Icl2 (also known as AceA) of Mycobacterium tuberculosis, respectively.(17) The two enzymes of the glyoxylate cycle, Icl and malate synthase, enable bacteria to divert citric acid cycle metabolites from decarboxylation to preserve carbon atoms, and are therefore essential for survival within macrophages. $(18,19)$ It is useful to note that itaconyl-CoA was reported to inhibit $B_{12}$-dependent methylmalonyl-CoA mutase (MCM; involved in replenishing the citric acid cycle via the degradation of odd-chain fatty acids and some amino acids) in $M$. tuberculosis(20) and in human.(21) M. tuberculosis MCM shows high similarity to the corresponding S. Typhimurium and P. aeruginosa isoforms, suggesting that the latter two may also be inhibited by itaconyl-CoA.

Reports of the concentration of itaconate in macrophages vary significantly between groups and cell type. Within activated murine macrophages, the overall concentration of itaconate has been estimated to $3-8 \mathrm{mM},(1),(2)$ whereas this value is only $60 \mu \mathrm{M}$ in activated human macrophages.(2) Recently, a report has found that the concentration of itaconate within Salmonella-containing vacuoles in murine macrophages is approximate 5-6 mM.(22) In contrast, reported MICs for itaconate towards bacteria range from 1-75 mM.(2, 13, 15, 16, 23-26) For example, the itaconate MIC values are 6 mM for Vibrio spp.,(24) 10-20 mM for S. Typhimurium,(2, 15) 1 - $10 \mathrm{mM}$ for E. coli,(15, 25) A. baumannii,(13) MRSA,(13) L. pneumonophila,(13) and different Pseudomonas species, $(25,26)$ 25-50 mM for $M$. tuberculosis,(2) and >75 mM for $Y$. pestis.(23) Notably, in none of these reports was there a mention of the $\mathrm{pH}$ being controlled. 
From these numbers, whether the itaconate concentration in macrophage is high enough to effectively inhibit microbial growth has been questioned.(27) It could be argued that itaconate may accumulate within specific organelles such as the mitochondria (where it is produced) and the phagolysosomes, thereby reaching concentrations high enough to inhibit bacterial growth in these structures. It has recently been demonstrated that itaconate is transported to vacuoles containing Salmonella,(22) consistent with itaconate playing an antimicrobial role even at cellular concentrations of 5-6 mM, i.e. below the reported MIC of itaconate against Salmonella. $(2,15)$ Furthermore, the amount of itaconate needed to inhibit bacterial growth may depend (via a synergistic, additive or antagonistic relationship) on the environment, e.g. the presence of reactive oxygen species and reduced $\mathrm{pH}$ of phagolysosomes.

Itaconic acid has pKa values of 3.85 and $5.45,(28)$ and is therefore acidic enough to significantly alter the $\mathrm{pH}$ of solutions such as growth media (buffered or not). Authors of previous articles reporting the activity of itaconate against specific bacteria have used commercial itaconic acid (not a neutralized form such as disodium itaconate) in their experiments, without assessing its effect on the $\mathrm{pH}$ of the growth media.(2, 13, 15, 23-26) Bacterial growth is well-known to be affected by $\mathrm{pH}$ (vide infra), and failure to ensure a constant $\mathrm{pH}$ may considerably skew MIC measurements. A recent report has suggested that there may be synergy between $\mathrm{pH}$ and itaconate activity,(29) but a systematic exploration of the phenomenon has yet to be reported.

Antibiotic resistance is a global health crisis. Extensive use of antibiotics has led to the rapid spread of antibiotic resistance, with an increasing number of multidrug resistant, extremedrug resistant, and pan-drug resistant bacterial strains. $(30,31)$ As such, not only do we urgently need new antibiotics, but also alternative microbial targets and innovative ways to treat 
infections. In light of the increasingly recognized importance of itaconate during the innate immune response to infection, we report a systematic study of the effect of $\mathrm{pH}$ on its antimicrobial activity against various bacterial strains. The data presented confirm the acidifying effect of itaconate at low millimolar concentrations and demonstrate a synergistic antibacterial activity between itaconate and the acidity of the medium. Our results are consistent with itaconate playing an antimicrobial role in macrophages. Taken together, our data agree with the proposal that inhibitors of itaconate degradation may offer a new strategy to treat infections.

\section{Results}

\section{Acidity of itaconic acid}

We observed that the addition of itaconic acid to M9A growth medium (pH pre-adjusted to 7.2) has a considerable effect on the final $\mathrm{pH}$ of the medium, with a 2 units decrease at $40 \mathrm{mM}$ itaconic acid (Figure 2). 


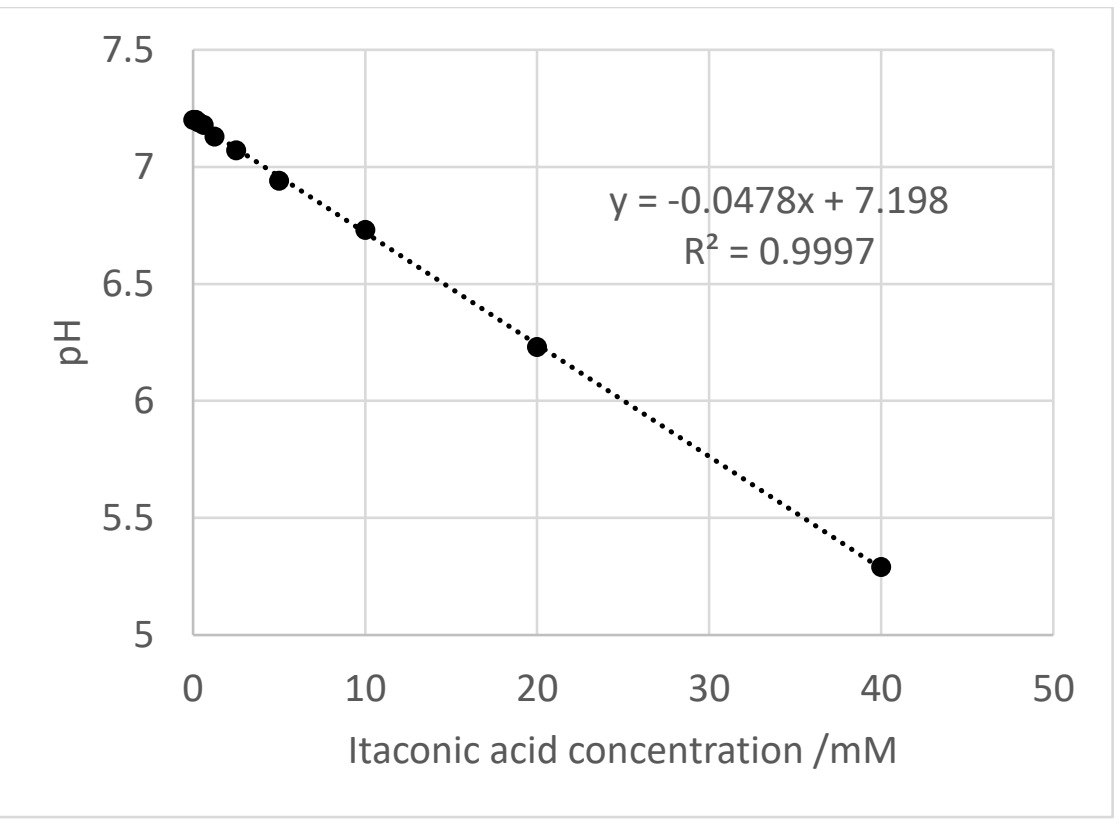

Figure 2: Change in $\mathrm{pH}$ of M9A medium (pH initially set to 7.2) with increasing concentration of itaconic acid.

We next contrasted the effects of itaconic acid and disodium itaconate on the growth of several pathogenic species and report this data here as MIC values (Table 1). Unlike itaconic acid, disodium itaconate does not affect the $\mathrm{pH}$ of the growth medium significantly. In all cases, the bacteria were more susceptible to itaconic acid than to disodium itaconate, demonstrating that the $\mathrm{pH}$ is affecting the antimicrobial activity of itaconate. Interestingly, two bacterial species that have previously not been described to have an itaconate-degradation pathway, Acinetobacter baumannii and Enterococcus faecium, both have an $\mathrm{MIC}_{90}$ value for itaconic acid that is similar to those of known itaconate-metabolising bacteria such as $S$. Typhimurium and $P$. aeruginosa. This suggests that $A$. baumanii and E. faecium may have a previously-undescribed itaconate degradation pathway, or some other mechanism to confer itaconate resistance. Itaconate 
degradation inhibitors may therefore also resensitize these strains to itaconate produced by macrophages.

Table 1: MIC 90 of itaconic acid and disodium itaconate for different pathogens (unadjusted pH)

MIC $_{90}$ of itaconic acid

Species
MIC 90 of disodium

\section{Escherichia coli}

Salmonella enterica spp.

Typhimurium
itaconate (mM)
$(\mathrm{mM})$

$>40$

$10>40$

$$
>40
$$

\begin{tabular}{lcc}
\hline $\begin{array}{l}\text { Pseudomonas aeruginosa } \\
\text { Klebsiella pneumoniae }\end{array}$ & 20 & $>40$ \\
\hline Acinetobacter baumannii & 20 & $>40$ \\
\hline Enterobacter faecium & 20 & $>40$ \\
\hline Mycobacterium tuberculosis & $1^{*}$ & \\
\hline *these values are not MIC ${ }_{90}$ but MIC $C_{99}$, and were measured in the presence of detergent and \\
under conditions where the glyoxylate shunt is essential
\end{tabular}

\section{Antimicrobial activity of itaconate towards $E$. coli at controlled pH}

We elected to perform further studies with E. coli, as a model of a bacterium that does not encode itaconate-degrading enzymes and is therefore sensitive to itaconate. Cell growth was initially monitored at $\mathrm{pH}$ values ranging from 5.0 to 7.2 in M9A media without itaconate. Whereas 
E. coli was found to proliferate equally well from $\mathrm{pH} 7.2$ to $\mathrm{pH} 6.3$, growth was sharply hampered at $\mathrm{pH}$ values below 6.3 (Figure 3).

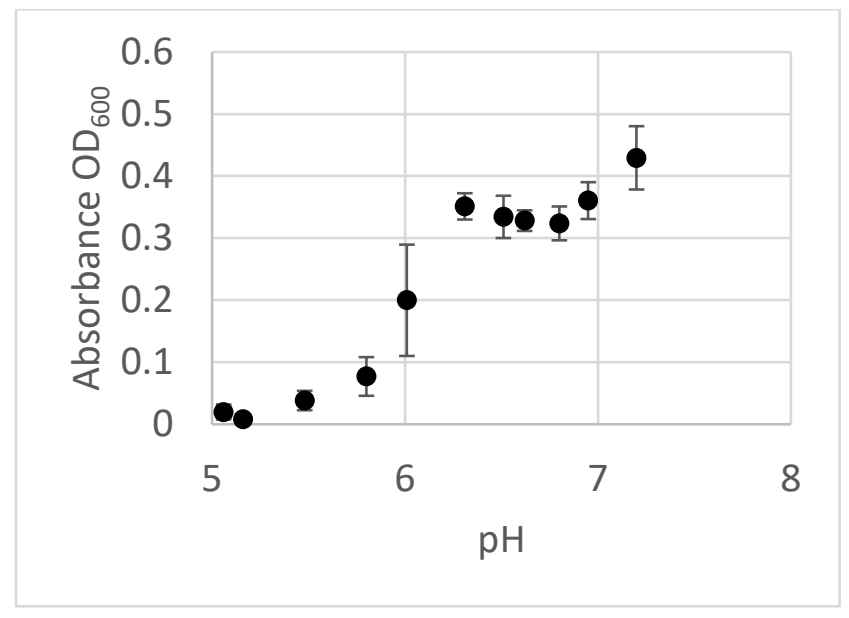

Figure 3: Growth of E. coli in M9A medium (without itaconate) for 72 hours adjusted to various pH

We next looked at the growth of $E$. coli in the presence of itaconate at controlled $\mathrm{pH}$, for $\mathrm{pH}$ values ranging from 6.4 to 7.2 (a pH range in which the bacterium grows well). The effect of itaconate was found to vary significantly with $\mathrm{pH}$, revealing an increasing antimicrobial activity as the $\mathrm{pH}$ dropped. The data is presented as the relative growth, either with respect to $E$. coli grown at the same $\mathrm{pH}$ in the absence of itaconate (Figure 4A), or relative to the growth observed at $\mathrm{pH} 7.2$ in the absence of itaconate (Figure 4B), the latter of which better reveals the effect of $\mathrm{pH}$. MIC values were derived for itaconate at each $\mathrm{pH}$ using the data from Figure 4A. Interestingly, we noticed an increased bacterial growth at the lowest itaconate concentrations tested (ca. 0.37 $\mathrm{mM}$ ) for $\mathrm{pH} 7.0$ and above. This was not expected since $E$. coli is not believed to express itaconatemetabolizing enzymes, and hence should not be able to use itaconate as a carbon source. It is however known that succinyl coenzyme A synthetase (sucCD) has weak affinity for itaconate,(32) 
and as such itaconate may compete with the formation of succinyl-CoA from succinate $\left(K_{m}\right.$ succinate $=0.141 \mathrm{mM}, K_{m}$ itaconate $\left.=0.475 \mathrm{mM}\right)$, thereby slightly increasing the concentration of succinate which feeds into the citric acid cycle.

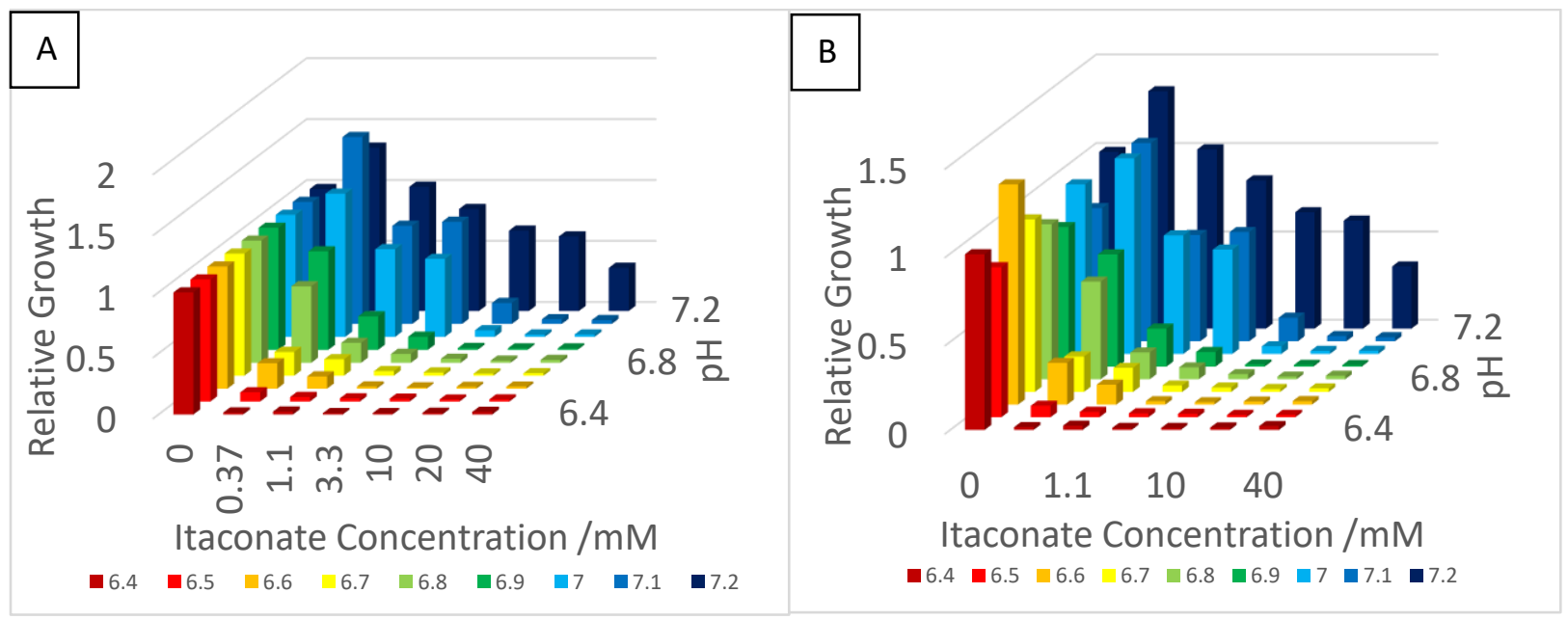

Figure 4: Relative growth of E. coli over 72 hours in the presence of various concentrations of itaconate at controlled $\mathrm{pH}$ values within 6.4 to 7.2. A) Growth is presented as relative to $0 \mathrm{mM}$ itaconate within each $\mathrm{pH}$ value. $\mathrm{B}$ ) Growth is presented as a value relative to $0 \mathrm{mM}$ itaconate at pH 7.2

From these data, the $\mathrm{MIC}_{90}$ of itaconate was calculated at different $\mathrm{pH}$ (Table 2), and the values were used to evaluate possible synergy between itaconate and $\mathrm{pH}$ towards $E$. coli using fractional inhibitory coefficients (FICs), where $F I C=\left(M_{1} C_{90} A_{\text {combination } A+B} / \mathrm{MIC}_{90} A\right)+\left(M_{90}\right.$ $B_{\text {combination } A+B} / M_{1} C_{90} B$ ), $A$ is the concentration of $\mathrm{H}^{+}$, and $B$ is the concentration of itaconate (see supporting information for details). The concentration of $\mathrm{H}^{+}$was calculated from Figure 2. In aqueous buffer, however, the concentration of $\mathrm{H}+$ cannot be set to 0 , making it impractical to determine an MIC of itaconate in the absence of $\mathrm{H}+$. It was therefore decided to use $\mathrm{pH} 7.2$ as the standard condition to measure the $\mathrm{MIC}_{90}$ of itaconate, which was found to be $80 \mathrm{mM}$ (Figure S1). 
FIC values below 0.5 indicate synergy, those within $0.5-1$ suggest an additive effect, within $1-4$ imply indifference, and greater than 4 are indicative of an antagonistic relationship.(33) For E. coli exposed to itaconate at different $\mathrm{pH}$, all FIC values are less than 0.5, consistent with synergy between itaconate and acidity.

Table 2: Calculated FIC values for E. coli growth at different concentrations of itaconate and $\mathrm{pH}$, where + denotes growth, - denotes no growth.

\begin{tabular}{|c|c|c|c|c|c|c|c|}
\hline \multirow{2}{*}{$\mathrm{pH}$} & \multicolumn{7}{|c|}{$[\mathrm{ITA}](\mathrm{mM})$} \\
\hline & 0 & 0.37 & 1.1 & 3.3 & 10 & 20 & 40 \\
\hline 6.4 & + & 0.4 & - & - & - & - & - \\
\hline 6.5 & + & 0.3 & - & - & - & - & - \\
\hline 6.6 & + & + & 0.3 & - & - & - & - \\
\hline 6.7 & + & + & + & 0.2 & - & - & - \\
\hline 6.8 & + & + & + & 0.2 & - & - & - \\
\hline 6.9 & + & + & + & 0.2 & - & - & - \\
\hline 7.0 & + & + & + & + & 0.2 & - & - \\
\hline 7.1 & + & + & + & + & + & 0.3 & - \\
\hline 7.2 & + & + & + & + & + & + & + \\
\hline
\end{tabular}

Antimicrobial activity of itaconate in Salmonella enterica serovar Typhimurium at controlled

pH

We next focused on $S$. Typhimurium, a bacterium that, unlike E. coli, proliferates in macrophages and is known to encode itaconate-degrading enzymes. The cells were first allowed 
to grow in M9A media at $\mathrm{pH}$ values from 5.0 to 7.2 , without itaconate. Our data show that, similar to $E$. coli, in the absence of itaconate $S$. Typhimurium grows equally well at $\mathrm{pH}$ values between 7.2 and 6.3 , but poorly at pH 6.0 and below (Figure 5).

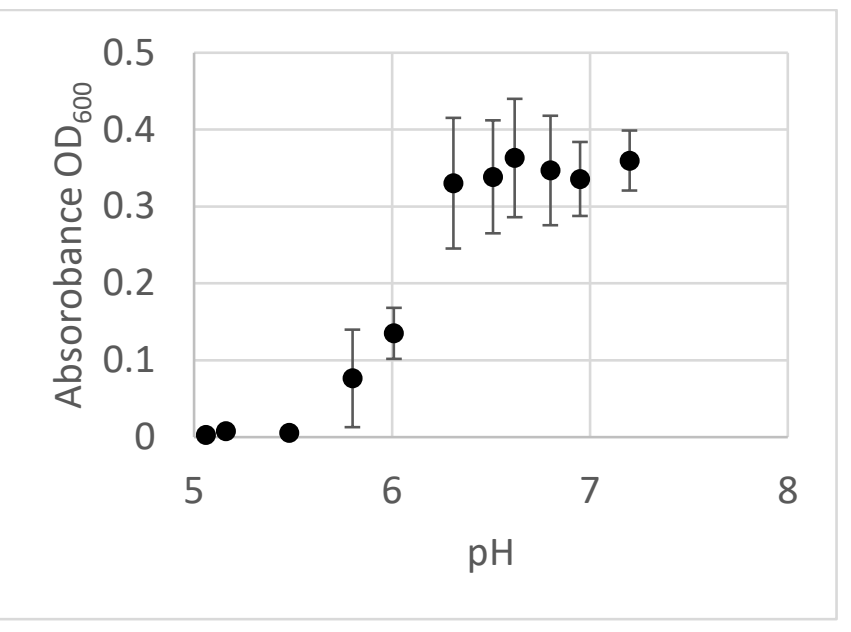

Figure 5: Growth of S. enterica spp. Typhimurium for 72 hours in M9A medium adjusted to various pH

We next looked at bacterial growth in the presence of various concentrations of itaconate, at several controlled pH values. Importantly, as expected from its ability to metabolize itaconate to AcCoA and pyruvate, S. Typhimurium was in general much more resistant to itaconate than E. coli (about 5-fold at $\mathrm{pH} 7.2$ and $>500$-fold at $\mathrm{pH} 6.4$ ). As expected, we observed that the susceptibility of $S$. Typhimurium to itaconate was highly dependent on the $\mathrm{pH}$ of the medium and increased with acidity. For example, the $\mathrm{MIC}_{90}$ of itaconate is $400 \mathrm{mM}$ at pH 7.2, 200 $\mathrm{mM}$ at $\mathrm{pH} 6.5$, and $3.7 \mathrm{mM}$ at $\mathrm{pH}$ 6.0. The data presented in Figure $6 \mathrm{~A}$ shows the growth of $S$. Typhimurium at a given $\mathrm{pH}$ value relative to its growth at the same $\mathrm{pH}$ in the absence of itaconate, whereas Figure $6 \mathrm{~B}$ displays the same data plotted relative to the growth of $S$. Typhimurium at $\mathrm{pH}$ 
7.2 in the absence of itaconate. FIC calculations (Table 3) revealed a synergistic relationship between itaconate and acidity at $\mathrm{pH}$ values below 6.3 and was otherwise additive.
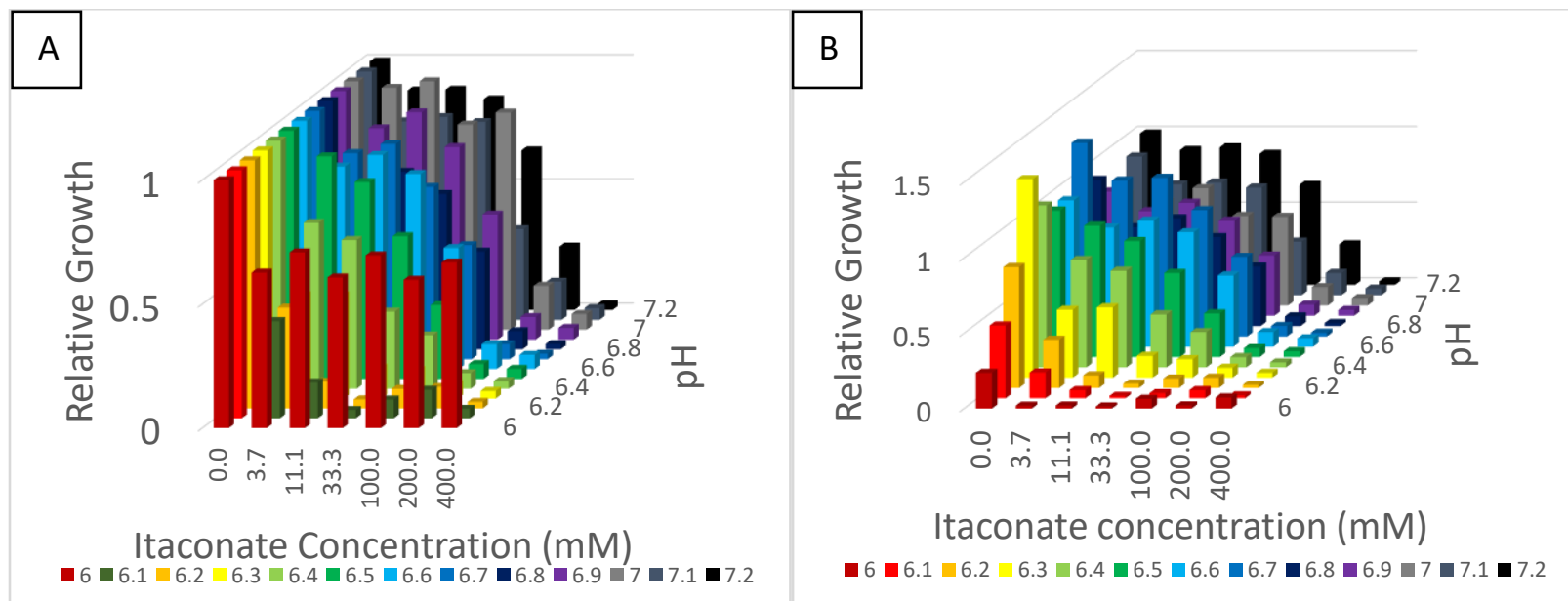

Figure 6: Relative growth of S. Typhimurium over 72 hours in the presence of various concentrations of itaconate at controlled $\mathrm{pH}$ values within 6.0 to 7.2. A) Growth is presented as relative to $0 \mathrm{mM}$ itaconate within each $\mathrm{pH}$ value. B) Growth is presented as a value relative to 0 $m M$ itaconate at $\mathrm{pH}$ 7.2.

Table 3: Calculated FIC values for S. Typhimurium growth at different concentrations of itaconate and $\mathrm{pH}$, where + denotes growth, - denotes no growth.

\section{[ITA] (mM)}

$\mathrm{pH}$

\begin{tabular}{lllllll}
\hline 0 & 3.7 & 11 & 33 & 100 & 200 & 400
\end{tabular}

$\begin{array}{llllllll}6.0 & + & 0.3 & - & - & - & -\end{array}$

\begin{tabular}{llllllll}
\hline 6.1 & + & + & 0.3 & - & - & -
\end{tabular}

\begin{tabular}{llllllll}
\hline 6.2 & + & + & 0.2 & - & - & - & - \\
\hline 6.3 & + & + & + & + & + & 0.7 & -
\end{tabular}

\begin{tabular}{|c|c|c|c|c|c|c|c|}
\hline 6.4 & + & + & + & + & + & 0.6 & - \\
\hline 6.5 & + & + & + & + & + & 0.6 & - \\
\hline
\end{tabular}




\begin{tabular}{llllllll}
\hline 6.6 & + & + & + & + & + & 0.6 & - \\
\hline 6.7 & + & + & + & + & + & 0.6 & - \\
\hline 6.8 & + & + & + & + & + & 0.6 & - \\
\hline 6.9 & + & + & + & + & + & 0.5 & - \\
\hline 7.0 & + & + & + & + & + & + & 1 \\
\hline 7.1 & + & + & + & + & + & + & 1 \\
\hline 7.2 & + & + & + & + & + & + & \\
\hline
\end{tabular}

\section{Discussion}

Herein, we have demonstrated that $\mathrm{pH}$ is a crucial variable when considering the antimicrobial activity of itaconate, and we propose that this sensitivity may also apply to other biological activities. We have established that the MIC of itaconic acid towards E. faecium and $A$. baumannii is similar to those of species known to metabolise itaconate (e.g. S. Typhimurium and $P$. aeruginosa), implying that $E$. faecium and $A$. baumanii may harbor a mechanism of resistance to itaconate. The lower MIC 99 values of itaconate towards $M$. tuberculosis reported here (1 - 4 $\mathrm{mM}$ ) compared to that previously reported $(25-50 \mathrm{mM})(2)$ may be explained by the different growth conditions used. Indeed, we used a non-metabolisable detergent whereas the previous report had not reported using a detergent, which may affect the ability of itaconate to penetrate the cells.

Based on the published MIC values of itaconate towards bacteria $(1-50 \mathrm{mM})$ and the reported cellular concentration of itaconate $(3-8 \mathrm{mM}$ in murine macrophages, and ca. $60 \mu \mathrm{M}$ in 
activated human macrophages) $(2,22)$, it is tempting to conclude that itaconate is unlikely to be produced by macrophages for its antimicrobial activity.(2) These reported MIC values however may not have been measured at constant $\mathrm{pH}$, and therefore may be biased. The local $\mathrm{pH}$ where the bacteria reside may affect the MIC of itaconate in vivo. For example, intracellular Salmonella are typically located in acidic vacuoles ( $\mathrm{pH}$ of ca. 5.0),(36) where the concentration of itaconate is 5-6 mM.(22) Consistent with an antimicrobial role for itaconate, we report herein that the MIC of itaconate is much lower at acidic $\mathrm{pH}$, with concentrations that are within those found in specific macrophage organelles. Other examples include phagosomes harboring a $\mathrm{pH}$ of $4.5-5.0$ within 10 minutes after phagocytosis,(34) while the early phagosome shows a pH of $6.1-6.5$, and the late phagosomes a $\mathrm{pH}$ of 5.5 -6.0.(35) In particular, Mycobacterium species-containing phagosomes have a pH within 5.2 -6.3, depending on the maturation phase.(37-39) Despite their poor growth in our media at lower $\mathrm{pH}$, it is well established that both E.coli $(\mathrm{pH} \geq 2.5)(40)$ and $S$. Typhimurium ( $\mathrm{pH} \geq 4.5)(41)$ tolerate acidic conditions.

Our results reveal that the antimicrobial activity of itaconate increases about 200-fold from $\mathrm{pH} 7.2$ to 6.4 for E. coli (Fig S4), and >100-fold when the $\mathrm{pH}$ drops from 7.2 to 6.0 for $S$. Typhimurium (Fig S5). Not only does the MIC drops with increasing acidity, but the effect is synergistic across all $\mathrm{pH}$ values tested for $E$. coli (Table 2), and at $\mathrm{pH}$ values of $\leq 6.2$ for $S$. Typhimurium (Table 3). At pH 6.0, the MIC 90 of itaconate in S. Typhimurium was found to be 3.7 $\mathrm{mM}$, within the concentration range of itaconate found within Salmonella-containing vacuoles,(22) implying a potential antimicrobial effect of itaconate. Importantly, the MIC 90 of itaconate remains nearly constant at $\mathrm{pH}$ values of 6.3 and above, suggesting that the acidity of itaconic acid alone is not sufficient to explain its antimicrobial activity. 
The physiological rationale for the observed synergy is still unclear, yet current knowledge allows us to postulate some contributing factors. For example, part of the synergy may result from an increased cell permeability of itaconate with protonation, although this is unlikely to be a major factor considering that there is no linear correlation between the growth of $E$. coli or $S$. Typhimurium and the concentration of monoanionic itaconate (ITA ${ }^{1-}$, Figures S2-S3, Table S1). Alternatively, an increased activity of dicarboxylate and/or mono-basic dicarboxylate transporters at lower pH may partly explain the observed synergy. Succinate transporters are especially relevant given that itaconate appears to be a substrate for enzymes that use or generate succinate, $(5,32,42)$ suggesting that this transporter may be involved in cell permeation of itaconate. The role of this transporter in the observed synergy is supported by evidence in $E$. coli that the transport of succinate and fumarate is affected by $\mathrm{pH}$, via an unknown regulation mechanism.(43) E. coli has an optimized succinate uptake at pH 6.(43) Specifically, it can use succinate (pKa 5.48, compared to 5.45 for itaconate)(28) as a carbon source at pH 6, but not fumarate (pKa 4.54)(44). It is speculated that since the second pKa of succinate is near 6 , the transporter discriminates between monoanions and dianions.(43) In support of this claim, monoanionic species such as short chain fatty acids and maleate (pKa 6.58)(44), were found more effective at inhibiting succinate uptake than di- and trianionic compounds and amino acids.(43) It has been shown that fumarate and malate (pKa 5.2)(44) are also able to compete with succinate for the transporter at $\mathrm{pH} 5,(45)$ whereas they can not at $\mathrm{pH}$ 6.(43) The specific transporter has been identified as DauA in E. coli(45) and S. Typhimurium.(46) A different transporter, namely $\mathrm{YaaH}$, functions to shuttle both acetate and succinate (with similar affinity) 
in $E$. coli, and is most effective at pH 6.0.(47) From a quick computational search we found an analogue of YaaH in S. enterica, referred to as SatP (Fig S7).

The antimicrobial role of itaconate is also consistent with the fact that several pathogens have evolved mechanisms to limit the harmful effect of itaconate, such as the itaconate degradation pathway encoded by S. Typhimurium, Y. pestis, and P. aeruginosa.(14) Also in agreement with this is the demonstration that $S$. Typhimurium can be resensitized to the antibacterial action of itaconate by small molecule inhibitors of the itaconate degradation pathway,(15) raising the interesting possibility that the antimicrobial activity of itaconate could be exploited to treat infections.

The relationship between macrophages and pathogens is complex, and the exact role played by itaconate remains to be fully clarified. Our results support an inhibitory activity on bacterial growth, in synergy with acidity. They also warrant a more systematic, documented control of the $\mathrm{pH}$ for all research involving itaconate, lest confounding factors misguide the interpretation of results.

\section{Materials and Methods}

Itaconic acid was purchased from Alfa Aesar, sodium carbonate was purchased from Fisher Scientific, disodium itaconate was prepared by mixing $\mathrm{Na}_{2} \mathrm{CO}_{3}(10.6 \mathrm{~g}, 100 \mathrm{mmol})$ with itaconic acid $(13.01 \mathrm{~g}, 100 \mathrm{mmol})$ in distilled water $(100 \mathrm{~mL})$ and stirred for 1 hour before removing the water in vacuo to produce a fine white powder. The white powder was incubated at $70^{\circ} \mathrm{C}$ overnight to remove residual water. Absorbance was measured using Spectramax ${ }^{\circledR} i 3 x$ microtiter plate reader from Molecular Devices. The bacterial strains used in these studies include: 
Escherichia coli $\left(\right.$ ATCC $^{\circledR}$ 25922), Salmonella enterica spp. Typhimurium (ATCC ${ }^{\circledR}$ 14028), Acinetobacter baumannii (ATCC ${ }^{\circledR}$ 19606), Enterobacter faecium (ATCC ${ }^{\circledR}$ 19434), Klebsiella pneumoniae $\left(\operatorname{ATCC}^{\circledR}\right.$ 13883), Pseudomonas aeruginosa $\left(\operatorname{ATCC}^{\circledR} 27853\right)$, and Mycobacterium tuberculosis H37Rv $\left(\operatorname{ATCC}^{\circledR}\left(25618^{\mathrm{TM}}\right)\right.$. Shel Lab $^{\circledR}$ rotary shakers were used for $10 \mathrm{~mL}$ incubations, and an Ohaus ${ }^{\circledR}$ benchtop orbital shaker was used for assay incubations. The rich media used for selected experiments were Difco ${ }^{\mathrm{TM}}$ Nutrient Broth (NB) except for $M$. tuberculosis where Middlebrook 7H9 media (Difco) supplemented with $0.05 \%$ albumin, $0.085 \%$ sodium chloride, 0.1\% acetate and $0.05 \%$ Tyloxaplol (7H9-acetate).was employed. The minimal growth media (M9A) recipe for $1 \mathrm{~L}$ is as follows: $6.8 \mathrm{~g} \mathrm{Na}_{2} \mathrm{HPO}_{4}, 3.0 \mathrm{~g} \mathrm{KH}_{2} \mathrm{PO}_{4}, 0.5 \mathrm{~g} \mathrm{NaCl}, 1.0 \mathrm{~g} \mathrm{NH} 4 \mathrm{Cl}, 4.0 \mathrm{~g}$ NaOAc, $2 \mathrm{~mL} \mathrm{MgSO}_{4}(62.5 \mathrm{mg} / \mathrm{mL}), 1 \mathrm{~mL} \mathrm{CaCl} 2(11.3 \mathrm{mg} / \mathrm{mL})$, and $150 \mu \mathrm{L}$ trace elements solution (162 mg FeCl $3,13.6 \mathrm{mg} \mathrm{ZnCl} 2,24.2 \mathrm{Na}_{2} \mathrm{MoO}_{4} \cdot 2 \mathrm{H}_{2} \mathrm{O}, 15.9 \mathrm{mg} \mathrm{CaCl}, 12.6 \mathrm{CuCl}_{2} \cdot 2 \mathrm{H}_{2} \mathrm{O}, 6.2 \mathrm{mg} \mathrm{H}_{3} \mathrm{BO}_{3}$ in $10 \mathrm{~mL} 1 \mathrm{M} \mathrm{HCl}$ ). The media were filter sterilized. The $\mathrm{pH}$-specific minimal media (M9A') were prepared as M9A medium, except that a combination of $\mathrm{AcOH} / \mathrm{NaOAc}$ was used to access the desired $\mathrm{pH}$ (ratios provided in the table below).

\begin{tabular}{lccccccccccc}
\hline $\mathrm{pH}$ & 5.0 & 5.1 & 5.3 & 5.6 & $\mathbf{5 . 9}$ & $\mathbf{6 . 2}$ & $\mathbf{6 . 4}$ & $\mathbf{6 . 6}$ & $\mathbf{6 . 7}$ & $\mathbf{6 . 9}$ & $\mathbf{7 . 2}$ \\
\hline $\mathrm{AcOH}$ & 1 & 0.9 & 0.8 & 0.7 & 0.6 & 0.5 & 0.4 & 0.3 & 0.2 & 0.1 & 0 \\
\hline $\mathrm{NaOAc}$ & 0 & 0.1 & 0.2 & 0.3 & 0.4 & 0.5 & 0.6 & 0.7 & 0.8 & 0.9 & 1
\end{tabular}

\section{$\mathrm{MIC}_{90}$ assays of itaconic acid and disodium itaconate at uncontrolled $\mathrm{pH}$}

Bacteria were allowed to grow overnight in NB (loop from frozen stock into $10 \mathrm{~mL}$ at $37^{\circ} \mathrm{C}$ and $200 \mathrm{rpm}$ ) before plating onto NB agar and allowing to grow for $10-11$ hours at $37^{\circ} \mathrm{C}$. Four colonies 
were picked to inoculate NB liquid media $(10 \mathrm{~mL})$ and incubated until the stationary phase was reached, as measured by optical density at $600 \mathrm{~nm}$ (ca. 16 hours for E. coli; 24 hours for S. Typhimurium, A. baumannii, E. faecium, K. pneumoniae, and P. aeruginosa). An aliquot (100 $\mu \mathrm{L})$ of the culture was then transferred into M9A media $(10 \mathrm{~mL})$. The suspension was incubated at $37^{\circ} \mathrm{C}$ and $200 \mathrm{rpm}$ until $\mathrm{OD}_{600}$ reached 0.6 (ca. 8-10 hours for E. coli; ca. 24 hours for S. Typhimurium, A. baumannii, E. faecium, K. pneumoniae, and $P$. aeruginosa). This bacterial culture was used to inoculate $(10 \mu \mathrm{L}$ ) each well of a 96 -well microplate (flat colourless bottom) containing M9A and itaconic acid or disodium itaconate $(0.37,1.1,3.3,10,20,40 \mathrm{mM})$. Reference for relative growth was monitored in the absence of itaconic acid. Visible light absorption by the growth medium was subtracted from the readings. All data points are means of 3 separate experiments, each performed in triplicates. The plates were covered with a gas-permeable moisture barrier adhesive seal and incubated at $37^{\circ} \mathrm{C}$ and $250 \mathrm{rpm}$ for 72 hours.

\section{Resazurin microtiter assay (REMA) for M. tuberculosis}

Itaconic acid and disodium itaconate were tested separately against M. tuberculosis H37Rv using the resazurin microtiter assay (REMA) in 96-well plates as previously described.(48) Briefly, a midlogarithmic phase culture of H37Rv $\left(\mathrm{OD}_{600 \mathrm{~nm}}\right.$ approx. 0.5$)$ was diluted in 7H9 complete or 7H9acetate media to an $\mathrm{OD}_{600 \mathrm{~nm}}$ of 0.001 (approx. $1 \times 10^{5} \mathrm{CFU} / \mathrm{mL}$ ). Bacteria $(100 \mu \mathrm{L}$ ) were then dispensed in transparent flat-bottom 96 well plates. On each plate, controls without itaconate or itaconic acid and media alone were included. Plates were incubated for 6 days at $37^{\circ} \mathrm{C}$ before the addition of resazurin $(0.025 \% \mathrm{wt} / \mathrm{vol}$ to $1 / 10$ of the well volume). After overnight incubation, the fluorescence of the resazurin metabolite, resorufin, was determined with excitation at $560 \mathrm{~nm}$ and emission at $590 \mathrm{~nm}$, using a TECAN Infinite M200 microplate reader. The minimum inhibitory 
concentration ( $\mathrm{MIC}_{99}$, referred to as $\mathrm{MIC}$ ) was determined using the Gompertz equation with GraphPad Prism software (version 7). Itaconic acid and disodium itaconate were tested in triplicates.

\section{pH-controlled disodium itaconate MIC assay}

Bacteria were allowed to grow overnight in NB (loop from frozen stock into $10 \mathrm{~mL}$ at $37^{\circ} \mathrm{C}$ and $200 \mathrm{rpm}$ ) before plating onto NB agar and allowed to grow for $10-11$ hours at $37^{\circ} \mathrm{C}$. Four colonies were picked to inoculate NB liquid media $(10 \mathrm{~mL})$ and incubated until stationary phase, as measured by optical density at $600 \mathrm{~nm}$ (ca. 16 hours for E. coli; 24 hours for S. Typhimurium). An aliquot $(100 \mu \mathrm{L})$ of the culture was then transferred into M9A media $(10 \mathrm{~mL})$. The suspension was incubated at $37^{\circ} \mathrm{C}$ and $200 \mathrm{rpm}$ until $\mathrm{OD}_{600}$ reached 0.6 (ca. 8-10 hours for E. coli; ca. 24 hours for S. Typhimurium). This bacterial culture was used to inoculate $(10 \mu \mathrm{L})$ each well of a 96 -well microplate (flat colourless bottom) containing $\mathrm{M9A}^{\prime}$ adjusted to the desired $\mathrm{pH}$, and disodium itaconate $(0.37,1.1,3.3,10,20,40 \mathrm{mM}$ for $E$. coli, via addition of disodium itaconate in a MilliQ water solution, and 3.7, 11, 33, 100, 200, 400 mM for S. Typhimurium, via dissolution of disodium itaconate into $M 9 A^{\prime}$ ). Reference for relative growth was monitored in the absence of itaconic acid. Visible light absorption by the growth medium was subtracted from the readings. All data points are means of 3 separate experiments, each performed in triplicates. The plates were covered with a gas-permeable moisture barrier adhesive seal and incubated at $37^{\circ} \mathrm{C}$ and $250 \mathrm{rpm}$ for 72 hours.

\section{Acknowledgements}


This research was funded by the Canadian Institute of Health Research (CIHR grants PJ3-159883 and PJT-166175)), the Fonds de recherche du Quebec Audace program (FRQ grant AUDC263504), and the FRQ-RQRM-UdeM initiative.

\section{References}

1. Strelko CL, Lu W, Dufort FJ, Seyfried TN, Chiles TC, Rabinowitz JD, Roberts MF. 2011. Itaconic acid is a mammalian metabolite induced during macrophage activation. J Am Chem Soc 133:1638616389.

2. Michelucci A, Cordes T, Ghelfi J, Pailot A, Reiling N, Goldmann O, Binz T, Wegner A, Tallam A, Rausell A, Buttini M, Linster CL, Medina E, Balling R, Hiller K. 2013. Immune-responsive gene 1 protein links metabolism to immunity by catalyzing itaconic acid production. Proc Natl Acad Sci U S A 110:7820-7825.

3. O'Neill LAJ, Artyomov MN. 2019. Itaconate: the poster child of metabolic reprogramming in macrophage function. Nat Rev Immunol doi:10.1038/s41577-019-0128-5.

4. Cordes T, Michelucci A, Hiller K. 2015. Itaconic Acid: The Surprising Role of an Industrial Compound as a Mammalian Antimicrobial Metabolite. Annu Rev Nutr 35:451-473.

5. Lampropoulou V, Sergushichev A, Bambouskova M, Nair S, Vincent EE, Loginicheva E, CervantesBarragan L, Ma X, Huang SC, Griss T, Weinheimer CJ, Khader S, Randolph GJ, Pearce EJ, Jones RG, Diwan A, Diamond MS, Artyomov MN. 2016. Itaconate Links Inhibition of Succinate Dehydrogenase with Macrophage Metabolic Remodeling and Regulation of Inflammation. Cell Metab 24:158-166.

6. Qin W, Qin K, Zhang Y, Jia W, Chen Y, Cheng B, Peng L, Chen N, Liu Y, Zhou W, Wang YL, Chen X, Wang C. 2019. S-glycosylation-based cysteine profiling reveals regulation of glycolysis by itaconate. Nat Chem Biol 15:983-991. 
7. Nair S, Huynh JP, Lampropoulou V, Loginicheva E, Esaulova E, Gounder AP, Boon ACM, Schwarzkopf EA, Bradstreet TR, Edelson BT, Artyomov MN, Stallings CL, Diamond MS. 2018. Irg1 expression in myeloid cells prevents immunopathology during M. tuberculosis infection. J Exp Med 215:1035-1045.

8. Bambouskova M, Gorvel L, Lampropoulou V, Sergushichev A, Loginicheva E, Johnson K, Korenfeld D, Mathyer ME, Kim H, Huang L-H, Duncan D, Bregman H, Keskin A, Santeford A, Apte RS, Sehgal R, Johnson B, Amarasinghe GK, Soares MP, Satoh T, Akira S, Hai T, de Guzman Strong C, Auclair K, Roddy TP, Biller SA, Jovanovic M, Klechevsky E, Stewart KM, Randolph GJ, Artyomov MN. 2018. Electrophilic properties of itaconate and derivatives regulate the ІкBל-ATF3 inflammatory axis. Nature 556:501-504.

9. Mills EL, Ryan DG, Prag HA, Dikovskaya D, Menon D, Zaslona Z, Jedrychowski MP, Costa ASH, Higgins M, Hams E, Szpyt J, Runtsch MC, King MS, McGouran JF, Fischer R, Kessler BM, McGettrick AF, Hughes MM, Carroll RG, Booty LM, Knatko EV, Meakin PJ, Ashford MLJ, Modis LK, Brunori G, Sevin DC, Fallon PG, Caldwell ST, Kunji ERS, Chouchani ET, Frezza C, Dinkova-Kostova AT, Hartley RC, Murphy MP, O'Neill LA. 2018. Itaconate is an anti-inflammatory metabolite that activates Nrf2 via alkylation of KEAP1. Nature 556:113-117.

10. Seim GL, Britt EC, John SV, Yeo FJ, Johnson AR, Eisenstein RS, Pagliarini DJ, Fan J. 2019. Two-stage metabolic remodelling in macrophages in response to lipopolysaccharide and interferon-gamma stimulation. Nat Metab 1:731-742.

11. Cordes T, Lucas A, Divakaruni AS, Murphy AN, Cabrales P, Metallo CM. 2020. Itaconate modulates tricarboxylic acid and redox metabolism to mitigate reperfusion injury. Mol Metab 32:122-135.

12. Daniels BP, Kofman SB, Smith JR, Norris GT, Snyder AG, Kolb JP, Gao X, Locasale JW, Martinez J, Gale M, Jr., Loo YM, Oberst A. 2019. The Nucleotide Sensor ZBP1 and Kinase RIPK3 Induce the Enzyme IRG1 to Promote an Antiviral Metabolic State in Neurons. Immunity 50:64-76.e4. 
13. Naujoks J, Tabeling C, Dill BD, Hoffmann C, Brown AS, Kunze M, Kempa S, Peter A, Mollenkopf HJ, Dorhoi A, Kershaw O, Gruber AD, Sander LE, Witzenrath M, Herold S, Nerlich A, Hocke AC, van Driel I, Suttorp N, Bedoui S, Hilbi H, Trost M, Opitz B. 2016. IFNs Modify the Proteome of Legionella-Containing Vacuoles and Restrict Infection Via IRG1-Derived Itaconic Acid. PLoS Pathog 12:e1005408.

14. Sasikaran J, Ziemski M, Zadora PK, Fleig A, Berg IA. 2014. Bacterial itaconate degradation promotes pathogenicity. Nat Chem Biol 10:371-377.

15. Hammerer F, Chang JH, Duncan D, Castaneda Ruiz A, Auclair K. 2016. Small Molecule Restores Itaconate Sensitivity in Salmonella enterica: A Potential New Approach to Treating Bacterial Infections. Chembiochem 17:1513-1517.

16. McFadden BA, Purohit S. 1977. Itaconate, an isocitrate lyase-directed inhibitor in Pseudomonas indigofera. J Bacteriol 131:136-144.

17. Honer Zu Bentrup K, Miczak A, Swenson DL, Russell DG. 1999. Characterization of activity and expression of isocitrate lyase in Mycobacterium avium and Mycobacterium tuberculosis. J Bacteriol 181:7161-7167.

18. McKinney JD, Honer zu Bentrup K, Munoz-Elias EJ, Miczak A, Chen B, Chan WT, Swenson D, Sacchettini JC, Jacobs WR, Jr., Russell DG. 2000. Persistence of Mycobacterium tuberculosis in macrophages and mice requires the glyoxylate shunt enzyme isocitrate lyase. Nature 406:735738.

19. Fang FC, Libby SJ, Castor ME, Fung AM. 2005. Isocitrate lyase (AceA) is required for Salmonella persistence but not for acute lethal infection in mice. Infection and immunity 73:2547-2549.

20. Ruetz M, Campanello GC, Purchal M, Shen H, McDevitt L, Gouda H, Wakabayashi S, Zhu J, Rubin EJ, Warncke K, Mootha VK, Koutmos M, Banerjee R. 2019. Itaconyl-CoA forms a stable biradical in methylmalonyl-CoA mutase and derails its activity and repair. Science 366:589-593. 
21. Shen H, Campanello GC, Flicker D, Grabarek Z, Hu J, Luo C, Banerjee R, Mootha VK. 2017. The Human Knockout Gene CLYBL Connects Itaconate to Vitamin B12. Cell 171:771-782.e11.

22. Chen M, Sun H, Boot M, Shao L, Chang SJ, Wang W, Lam TT, Lara-Tejero M, Rego EH, Galán JE. 2020. Itaconate is an effector of a Rab GTPase cell-autonomous host defense pathway against Salmonella. Science 369:450-455.

23. Hillier S, Charnetzky WT. 1981. Glyoxylate bypass enzymes in Yersinia species and multiple forms of isocitrate lyase in Yersinia pestis. J Bacteriol 145:452-458.

24. Nguyen TV, Alfaro AC, Young T, Green S, Zarate E, Merien F. 2019. Itaconic acid inhibits growth of a pathogenic marine Vibrio strain: A metabolomics approach. Sci Rep 9:5937.

25. Bellion E, Kelley RL. 1979. Inhibition by itaconate of growth of methylotrophic bacteria. J Bacteriol 138:519-522.

26. Shimamoto G, Berk RS. 1980. Taurine catabolism. III. Evidence for the participation of the glyoxylate cycle. Biochim Biophys Acta 632:399-407.

27. Luan HH, Medzhitov R. 2016. Food Fight: Role of Itaconate and Other Metabolites in Antimicrobial Defense. Cell Metab 24:379-387.

28. Braude EA, Nachod, F. C. (ed). 1955. Determination of Organic Structures by Physical Methods. Academic Press, New York.

29. Zhu X, Lei H, Wu J, Li JV, Tang H, Wang Y. 2014. Systemic responses of BALB/c mice to Salmonella typhimurium infection. J Proteome Res 13:4436-4445.

30. Laxminarayan R, Duse A, Wattal C, Zaidi AK, Wertheim HF, Sumpradit N, Vlieghe E, Hara GL, Gould IM, Goossens H, Greko C, So AD, Bigdeli M, Tomson G, Woodhouse W, Ombaka E, Peralta AQ, Qamar FN, Mir F, Kariuki S, Bhutta ZA, Coates A, Bergstrom R, Wright GD, Brown ED, Cars O. 2013. Antibiotic resistance-the need for global solutions. Lancet Infect Dis 13:1057-1098. 
31. Mulani MS, Kamble EE, Kumkar SN, Tawre MS, Pardesi KR. 2019. Emerging Strategies to Combat ESKAPE Pathogens in the Era of Antimicrobial Resistance: A Review. Front Microbiol 10:539.

32. Nolte JC, Schurmann M, Schepers CL, Vogel E, Wubbeler JH, Steinbuchel A. 2014. Novel characteristics of succinate coenzyme A (Succinate-CoA) ligases: conversion of malate to malylCoA and CoA-thioester formation of succinate analogues in vitro. Appl Environ Microbiol 80:166176.

33. Doern CD. 2014. When does 2 plus 2 equal 5? A review of antimicrobial synergy testing. J Clin Microbiol 52:4124-4128.

34. Geisow MJ, D'Arcy Hart P, Young MR. 1981. Temporal changes of lysosome and phagosome pH during phagolysosome formation in macrophages: studies by fluorescence spectroscopy. The Journal of cell biology 89:645-652.

35. Flannagan RS, Cosio G, Grinstein S. 2009. Antimicrobial mechanisms of phagocytes and bacterial evasion strategies. Nat Rev Microbiol 7:355-366.

36. Alpuche Aranda CM, Swanson JA, Loomis WP, Miller SI. 1992. Salmonella typhimurium activates virulence gene transcription within acidified macrophage phagosomes. Proc Natl Acad Sci U S A 89:10079-10083.

37. MacMicking JD, Taylor GA, McKinney JD. 2003. Immune control of tuberculosis by IFN-gammainducible LRG-47. Science 302:654-659.

38. Schaible UE, Sturgill-Koszycki S, Schlesinger PH, Russell DG. 1998. Cytokine activation leads to acidification and increases maturation of Mycobacterium avium-containing phagosomes in murine macrophages. J Immunol 160:1290-1296.

39. Sturgill-Koszycki S, Schlesinger PH, Chakraborty P, Haddix PL, Collins HL, Fok AK, Allen RD, Gluck SL, Heuser J, Russell DG. 1994. Lack of acidification in Mycobacterium phagosomes produced by exclusion of the vesicular proton-ATPase. Science 263:678-681. 
40. Castanie-Cornet MP, Penfound TA, Smith D, Elliott JF, Foster JW. 1999. Control of acid resistance in Escherichia coli. J Bacteriol 181:3525-3535.

41. Wilmes-Riesenberg MR, Bearson B, Foster JW, Curtis R, 3rd. 1996. Role of the acid tolerance response in virulence of Salmonella typhimurium. Infect Immun 64:1085-1092.

42. Williams JO, Roche TE, McFadden BA. 1971. Mechanism of action of isocitrate lyase from Pseudomonas indigofera. Biochemistry 10:1384-1390.

43. Janausch IG, Kim OB, Unden G. 2001. DctA- and Dcu-independent transport of succinate in Escherichia coli: contribution of diffusion and of alternative carriers. Arch Microbiol 176:224-230.

44. Dawson RMC, Elliott, D.C., Elliott, W.H., Jones, K.M. 1959. Data for Biochemical Research, 1st ed. Clarendon Press, Oxford.

45. Karinou E, Compton EL, Morel M, Javelle A. 2013. The Escherichia coli SLC26 homologue YchM (DauA) is a C(4)-dicarboxylic acid transporter. Mol Microbiol 87:623-640.

46. Srinivasan L, Baars TL, Fendler K, Michel H. 2016. Functional characterization of solute carrier (SLC) 26/sulfate permease (SulP) proteins in membrane mimetic systems. Biochim Biophys Acta 1858:698-705.

47. Sa-Pessoa J, Paiva S, Ribas D, Silva IJ, Viegas SC, Arraiano CM, Casal M. 2013. SATP (YaaH), a succinate-acetate transporter protein in Escherichia coli. Biochem J 454:585-595.

48. Palomino JC, Martin A, Camacho M, Guerra H, Swings J, Portaels F. 2002. Resazurin microtiter assay plate: simple and inexpensive method for detection of drug resistance in Mycobacterium tuberculosis. Antimicrob Agents Chemother 46:2720-2722. 